\title{
Political Instability and Food Security
}

\author{
B. James Deaton, Bethany Lipka* \\ Department of Food, Agriculture and Resource Economics; University of Guelph, Ontario, Canada \\ *Corresponding author: woodsb@uoguelph.ca
}

Received March 12, 2015; Revised March 20, 2015; Accepted April 02, 2015

\begin{abstract}
In this paper we identify seven of the most food insecure countries of the developing world according to FAO data. These seven countries fall within both the quartile of developing countries with the highest prevalence of undernourishment and the quartile of developing countries with the highest increase in prevalence of undernourishment within the most recent five-year period recorded by the FAO. We provide a set of graphs and figures to further inform the relative position of these countries, as well as a comparison of determinants and measures of food security for these countries and the rest of the developing world. One relationship that is emphasized is the positive relationship between political stability and food security.
\end{abstract}

Keywords: food security, political instability, conflict, FAO

Cite This Article: B. James Deaton, and Bethany Lipka, "Political Instability and Food Security.” Journal of Food Security, vol. 3, no. 1 (2015): 29-33. doi: 10.12691/jfs-3-1-5.

\section{Introduction}

In 1996, at the World Food Summit (WFS), representatives from 185 countries throughout the world committed to "achieving food security for all" and to an "ongoing effort to eradicate hunger in all countries" [1]. Specifically, these countries committed to reducing the absolute number of chronically hungry people in the world by half by 2015. At the time, approximately 800 million people globally could be classified as not having enough food to meet their basic nutritional needs - roughly $16.6 \%$ of the global population [1,2]. Today, there are approximately 805 million people identified as hungry, $11.3 \%$ of the world's population [2], indicating how far this WFS goal is from being achieved. The proportional decline in hunger over the past two decades is, however, in keeping with the important - but less ambitious Millennium Development Goal (MDG) adopted in 2000. The first MDG set out to cut the proportion of the world's hungry in half between the years 1990 and 2015 [3]. In 1990, the proportion of undernourishment in developing regions was $23.2 \%$; today, it is $13.5 \%$ [2,3]. With respect to this goal, great progress has been made on aggregate; however, there remains a great deal of variation within and across countries.

This paper identifies a subset of countries that appear to be making the least progress towards food security ${ }^{1}$. The Venn diagram in Figure 1 illustrates the criteria used to identify this subset of countries. First, using the most recent FAO data, we identify the quartile of developing countries with the highest prevalence of undernourishment. This set is represented by circle $A$ in Figure 1 . Second, we identify the quartile of developing countries with the

${ }^{1}$ The World Bank (1986) defines food security as "access by all people at all times to sufficient food for an active, healthy life” [4]. highest increase in prevalence of undernourishment within the most recent five year period recorded by the FAO: i.e., $2010 / 12$ to $2012 / 14$. This set is represented by circle $B$ in Figure 1. For the purposes of this paper, the intersection of this set - i.e., $\mathrm{A} \cap \mathrm{B}$ - identifies the worst performing countries from the standpoint of food security statistics. Not only do these countries rank in the top quartile with respect to the current prevalence of undernourishment, but these countries also fall within the top quartile of countries with respect to growth in undernourishment over the past five years. This subset, $A \cap B$, includes the following countries: Afghanistan, Central African Republic, Haiti, Kenya, Pakistan, Swaziland and Uganda.

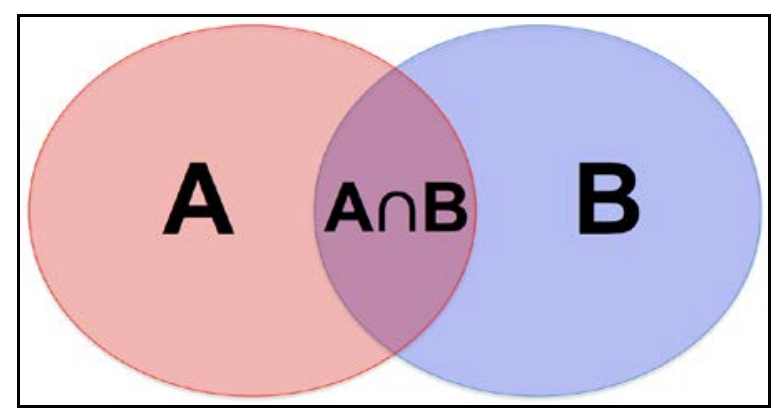

Figure 1. Subset of Countries Selected as 'Worst Performing' Countries with Respect to Current Undernourishment Rates.

Note: Circle A represents countries with a current prevalence of undernourishment that falls within the top quartile globally. Circle. B represents countries with a most recent five-year change in undernourishment that falls within the top quartile globally.

The remainder of this paper is focused on these 'worst performing' countries. We provide an exploration of determinants and measures of food security for the above listed countries within the context of FAO data. In a similar manner as Devereux (2009), who assessed common issues in three African countries (Ethiopia, Malawi, and Niger) that experienced famine in the twenty- 
first century, we illuminate a common issue that characterizes these countries: political instability [5]. In this regard, we have recast the FAO data in a manner that identifies and enhances our knowledge of the subset of countries falling the farthest behind in achieving the WFS commitment and the first Millennium Development Goal.

In the next section, Section 2, we review the 2014 FAO data, define key terms, and further characterize the worst performing countries with respect to food security. We provide figures that enable the reader to assess the characteristics of these countries relative to other countries throughout the developing world. Section 3 reviews key pathways to food security and why political instability inhibits the effective use of these.

\section{Data and Method}

The 'worst performing' countries, with respect to food security, fall within the quartile of developing countries with the highest current prevalence of undernourishment as calculated by the FAO, while also falling within the quartile of developing countries with the highest most recent five year change in the prevalence of undernourishment (2010/12 to 2012/14). The prevalence of undernourishment is defined by the FAO as "the probability that a randomly selected individual from the population consumes an amount of calories that is insufficient to cover his/her energy requirement for an active and healthy life" [2]. The FAO reports the prevalence of undernourishment for the developing world to be approximately $13.5 \%$, compared to a mean undernourishment rate of $30.3 \%$ among the seven poorest performing countries [2]. The mean change in undernourishment between 2010/12 and 2012/14 for all developing countries in the world was a reduction of $0.75 \%$, compared to an increase of $1.27 \%$ for the poorest performing countries we identified above.

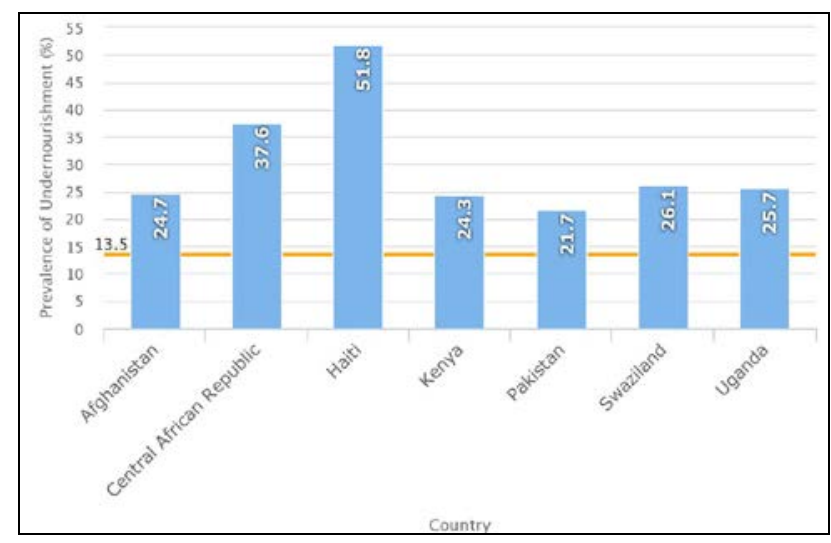

Figure 3. Current Prevalence of Undernourishment (2010/12-2012/14) - Worst Performing Countries

Figure 2 (see Appendix) plots the current prevalence of undernourishment against the most recent five-year change in undernourishment for the set of countries that experienced an increase in undernourishment over the most recent five-year period. This figure highlights the position of the seven countries we identify as the worst performing countries. Figure 3 compares the most recently calculated prevalence of undernourishment for each of the worst performing countries. The horizontal line identifies the average prevalence of undernourishment for all developing countries. In Figure 4, we provide a longitudinal comparison of trends in the prevalence of undernourishment for each of the worst performing countries, plotted against the developing world average. This figure provides information that spans the entire period that data has been collected by the FAO.

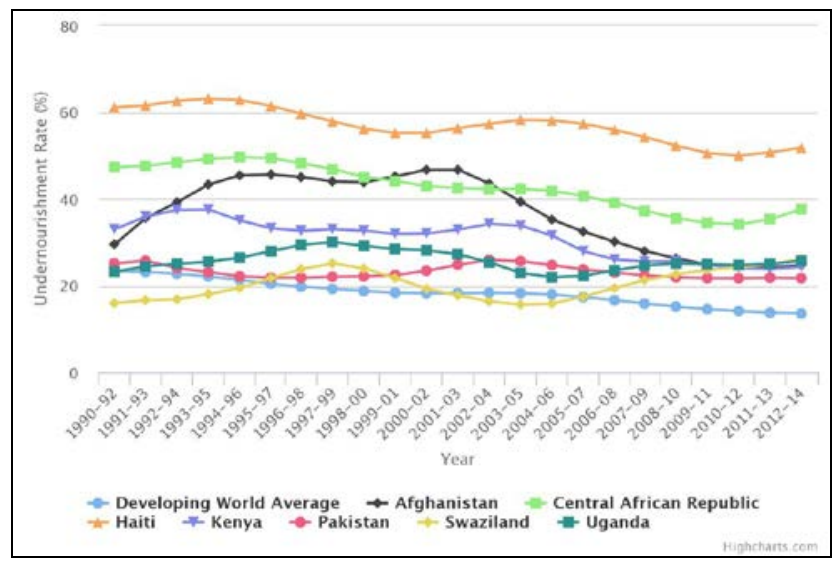

Figure 4. Longitudinal Trends in Undernourishment Rates - Worst Performing Countries (1990/92-2012/14)

The seven worst performing countries fall within three different FAO defined developing regions: sub-Saharan Africa (Central African Republic, Kenya, Swaziland and Uganda), Southern Asia (Afghanistan and Pakistan), and the Caribbean (Haiti). A comparison of this subset of countries, therefore, identifies key trends in food security determinants that remain consistent across different geographical regions. When contrasted with aggregate data for the developing world overall, these similarities become even more pronounced.

The FAO publishes data on a number of determinants and measures of food security. Table 1 (see Appendix) provides a comparison of means for these variables between the worst performing countries and the rest of the developing world ${ }^{2}$. We use t-tests to identify key variables that differentiate the worst performing countries from the rest of the developing world. The subheadings in this table indicate the FAO's key categorizations of determinants and measures of food security, or 'four pillars' of food security, namely: availability, access, stability and utilization. A number of these variables have a difference of means that is statistically significant between the worst performing countries and the rest of the developing world. Specifically, we note the importance of the index of political stability and the absence of violence and terrorism. We explore this variable more fully below.

There is a long list of historical and cultural conflicts, and catastrophes (e.g., Haiti's 2010 earthquake), that meaningfully differentiate these countries from each other and explain the underlying causes of both their present day food insecurity and political instability. For the purposes of our focus, we note that political stability (see Table 1, subheading 'Stability'), which emerges as having one of the largest and most significant differences of

${ }^{2}$ In cases where data for one or more of the worst performing countries were unavailable, that determinant or measure of food security was omitted. This resulted in the omission of the following variables: percentage of paved roads over total roads, road density, rail lines density, domestic food price index and domestic food price volatility. 
means, is the FAO published index measuring political stability and the absence of violence and terrorism.

The value for this political stability index measure ranges between approximately 2.5 (most stable) and -2.5 (least stable), and measures "...the perceptions of the likelihood that the government will be destabilized or overthrown by unconstitutional or violent means, including politically-motivated violence and terrorism" [2]. This index is listed as one of the World Bank's WorldWide Governance indicators [6], and is calculated based on data from four key categories of sources: 1) surveys of households and firms, 2) commercial business information providers, 3) Non-governmental organizations (NGOs) and 4) public sector organizations [2] $]^{3}$. The value of this index is below zero for all seven worst performing countries (ranging from -0.4 to -2.68 ) compared to a range from -2.89 to 1.53 for developing countries overall; and the mean measure for this determinant for these seven countries is -1.48 compared to a mean of 0.04 for the rest of the developing word.

The contrast in these index values between the worst performing countries and the rest of the developing world underscores the important relationship between political stability and food security. Though the direction of causation is not clear - i.e., countries prone to food security concerns may be more likely to experience political instability and conflict as a result - we overview how political instability threatens food security.

\section{Political Instability and Food Security}

Devereux (2009) ${ }^{4}$ points out that Food Security is obtained through three primary pathways: food production, exchange for food, and food transfers (e.g., food aid) [5]. The effectiveness of each of these pathways requires institutions that successfully coordinate future expectations; hence, it is unsurprising that political instability and food insecurity go hand-in-hand.

Food production, for example, requires farmers to make costly investments of labor and inputs long before any benefits can be reaped by harvest at a future date. Similarly, badly needed investment in soil conservation e.g., leaving land fallow, reducing intensification, no-till planting practices, etc. - require farmers to forego benefits today for the potential of even greater benefits in the future. Unfortunately, as is the case in countries characterized by political instability, an uncertain future diminishes the expected return of these tradeoffs. As a result, the potential of this pathway is greatly diminished.

The second pathway - exchange - is similarly limited by political instability. Sen (1981) argues persuasively that famines are not the result of a lack of food to eat; rather, famines should be understood as the result of people not eating enough food [5,7]. The emphasis on the latter underlines the importance of the many dimensions associated with accessing food. These dimensions include adequate earnings to afford purchasing food,

\footnotetext{
${ }^{3}$ There are a total of 32 data sources used to create the index, using a statistical method known as an unobserved components model. A list of these sources, as well as an overview of the methodology used in the index calculation, can be found on the WorldWide Governance Indicators website, here:

http://info.worldbank.org/governance/wgi/index .aspx\#doc.

${ }^{4}$ This point builds on Sen’s (1981) earlier research [7].
}

transportation infrastructure, and the protection of transport and property rights that enable exchange across increasing distances with increasingly unfamiliar agents. This latter point of emphasis - i.e., exchange across increasing distances with increasingly unfamiliar agents focuses food security on a regional basis rather than at the country level. A country, for example, may experience drought. However, the deleterious effects of the drought can be off set by trade between countries. Political instability in the country of need undermines this potential.

Political instability has a particularly pernicious effect on the capacity of the poor to generate incomes in the nonagricultural sector and thereby purchase food. The capacity of a country to develop alternative industries e.g., manufacturing - central to enabling economic growth $^{5}$, requires investment in property, machinery, and often, foreign direct investment. Countries characterized by political instability will require higher expected rates of return in order to induce the long-term investments necessary for the development of a manufacturing sector. This risk-premium reduces the level of investment and, as a consequence, diminishes the development of the nonagricultural sector and the associated income earnings that might enable the purchase of food when home production is limited or influenced by any number of shocks (e.g., extreme weather events).

Finally, food transfers are severely limited by political instability. There are many examples of cases where food aid efforts have been cancelled or suspended when instability and violence jeopardize the health and well being of aid workers. For example, in one of our worst performing countries, the Central African Republic, food aid was suspended in 'rebel held' territories [9]. In a new study by Nunn and Qian (2014) the complexities of Food Aid in areas of political instability is developed more fully [10]. In addition to these issues of food aid security, in areas of civil conflict food aid is also subject to theft by warring factions, which directly limits the capacity of aid to target its recipients. Theft also has an additional, unintended, effect; Nunn and Qian (2014) find empirical evidence that the capture of aid increases the incidence and duration of civil conflicts (in countries with a history of civil conflict) because it essentially supplements the food needs of warring factions who capture the food [10]. In this regard, political instability greatly diminishes the effectiveness of Food Aid.

\section{Discussion}

There are many factors that cause political instability. Conflicts over controlling land are perhaps the most common. Indeed, Holden, Deininger, and Ghebru (2010) argue that conflict over controlling territory is the "[...] largest category of causes of inter-state and intra-state conflicts” globally [11]. Countries characterized by political insecurity will, for reasons identified above, continue to face challenges with respect to food security.

This paper identifies the worst performing countries with respect to food security: Afghanistan, Central African Republic, Haiti, Kenya, Pakistan, Swaziland and Uganda.

\footnotetext{
${ }^{5}$ See Studwell (2013) review of economic development in Asia for a historic account of this dynamic [8].
} 
More specifically, these countries constitute both the upper quartile of countries with respect to the prevalence of under nourishment, and with respect to increases in the prevalence of undernourishment. As reviewed in Table 1, these countries differ significantly from the other countries in a number of key underlying factors often used to explain food security: availability, access, stability, and utilization. Recognizing, the complexities that meaningfully differentiate these countries, we focused our discussion on one central tendency that seemed important for many of the countries identified: political stability. Our review of the data and our exploration of this issue is intended to support future research and discussion.

\section{References}

[1] FAO. 1996. Rome Declaration on World Food Security. World Food Summit, 13-17 of November 1996, Rome Italy. http://www.fao.org/wfs/index_en.htm (accessed from FAO Corporate Document Repository, 13 January 2015).

[2] FAO. 2014. Food Security Indicators [excel spreadsheet]. http://www.fao.org/economic/ess/ess-fs/ess-fadata/en/\#.VLWIet54 pSw (accessed from FAO Economic and Social Development Statistics Database, 13 January 2015).

[3] UN. 2013. Goal 1: 2013 Factsheet. We Can End Poverty Millenium Development Goals and Beyond 2015. http://www.un.o rg/millenniumgoals/pdf/Goal_1_fs.pdf (accessed 13 January 2015).

Table 1. Determinants of Food Security - Comparison of Means Between Worst Performing Countries and Rest of Developing World

\begin{tabular}{|c|c|c|c|c|c|}
\hline & \multicolumn{2}{|c|}{$\begin{array}{l}\text { Worst Performing } \\
\text { Countries }\end{array}$} & \multicolumn{2}{|c|}{$\begin{array}{l}\text { Rest of Developing } \\
\text { World }\end{array}$} & \multirow[t]{2}{*}{ t-test } \\
\hline & Mean & Std. Err. & Mean & Std. Err. & \\
\hline \multicolumn{6}{|l|}{ Availability } \\
\hline Average Dietary Energy Supply Adequacy & 99.14 & 2.69 & 123.06 & 1.12 & $4.53^{* * *}$ \\
\hline Average Value of Food Production & 168.43 & 19.83 & 285.01 & 18.94 & 1.19 \\
\hline $\begin{array}{c}\text { Share of Dietary Energy Supply Derived From Cereals, Roots and } \\
\text { Tubers }\end{array}$ & 57 & 3.78 & 47.62 & 1.14 & $-1.72 * *$ \\
\hline Average Protein Supply & 55.57 & 2.32 & 80.57 & 1.56 & $3.37 * * *$ \\
\hline Average Supply of Protein of Animal Origin & 16.29 & 2.15 & 36.05 & 1.58 & $2.64 * *$ \\
\hline \multicolumn{6}{|l|}{ Access } \\
\hline Gross Domestic Product Per Capita (in Purchasing Power Equivalent) & 2676.69 & 784.58 & 16304.4 & 1445.99 & $1.96 * *$ \\
\hline Prevalence of Undernourishment & 30.27 & 4.07 & 13.31 & 0.97 & $-4.33^{* * *}$ \\
\hline Depth of the Food Deficit & 235.43 & 50.95 & 91.23 & 7.91 & $-4.32 * * *$ \\
\hline Prevalence of Food Inadequacy & 39.49 & 3.84 & 19.24 & 1.21 & $-4.18 * * *$ \\
\hline \multicolumn{6}{|l|}{ Stability } \\
\hline Cereal Import Dependency Ratio & 32.77 & 9.10 & 47.57 & 2.93 & 1.03 \\
\hline Percent of Arable Land Equipment for Irrigation & 25.37 & 13.27 & 28.99 & 2.37 & 0.30 \\
\hline Value of Food Imports in Total Merchandise Exports & 72 & 34.06 & 49.32 & 8.44 & -0.50 \\
\hline Political Stability and Absence of Violence/Terrorism & -1.48 & 0.33 & 0.04 & 0.07 & $4.09 * * *$ \\
\hline Per Capita Food Production Variability & 4.23 & 0.90 & 11.73 & 0.84 & $1.65^{*}$ \\
\hline Per Capita Food Supply Variability & 30.86 & 7.47 & 34.49 & 1.63 & 0.46 \\
\hline \multicolumn{6}{|l|}{ Utilization } \\
\hline Access to Improved Water Sources & 70.97 & 3.95 & 89.32 & 1.07 & $3.35^{* * *}$ \\
\hline Access to Improved Sanitation Facilities & 34.79 & 4.94 & 74.46 & 2.22 & $3.55^{* * *}$ \\
\hline Prevalence of Anaemia Among Pregnant Women & 42.09 & 3.07 & 32.52 & 0.80 & $-2.35^{* *}$ \\
\hline Prevalence of Anaemia Among Children Under 5 Years of Age & 55.01 & 4.00 & 37.26 & 1.35 & $-2.60 * * *$ \\
\hline
\end{tabular}

[4] World Bank. 1986. Poverty and Hunger: Issues and Options for Food Security in Developing Countries. A World Bank Policy Study. http://www-wds.worldbank.org/external/default/WDSCont entServer/WDSP/IB/1999/09/17/000178830_98101901455676/Re ndered/PDF/multi_page.pdf (accessed 5 January 2015).

[5] Devereux, S. 2009. Why does famine persist in Africa? Food Security 1 (1): 25-35.

[6] World Bank Group. 2014. The Worldwide Governance Indicators (WGI) Project. http://info.worldbank.org/governance/wgi/index.as px\#home (accessed 18 January 2015).

[7] Sen, A. 1981. Poverty and Famines: An essay on entitlement and deprivation. Oxford, UK: Oxford University Press.

[8] Studwell, J. 2013. How Asia Works: Success and Failure in the World's Most Dynamic Region. New York, NY: Grove Press.

[9] Lambers, W. 2013. War and Hunger in the Central African Republic. Think Africa Press. http://thinkafricapress.com/centralafrican-republic/war-and-hunger-central-african-republic (accessed 4 March 2015).

[10] Nunn and Qian. 2014. US Food Aid and Civil Conflict. American Economic Review 104 (6): 1630-1666.

[11] Holden, S.T., Deininger, K. and H. Ghebru. 2010. Impact of Land Registration and Certification on Land Border Conflicts in Ethiopia. Paper presented at the World Bank Annual Conference on Land Policy and Administration in Washington DC, April 2627, 2010. http://siteresources.worldbank.org/EXTARD/Resources/ 336681-1236436879081/5893311-1271205116054/HoldenPaper.p df (accessed 11 March 2015).

\section{Appendix}




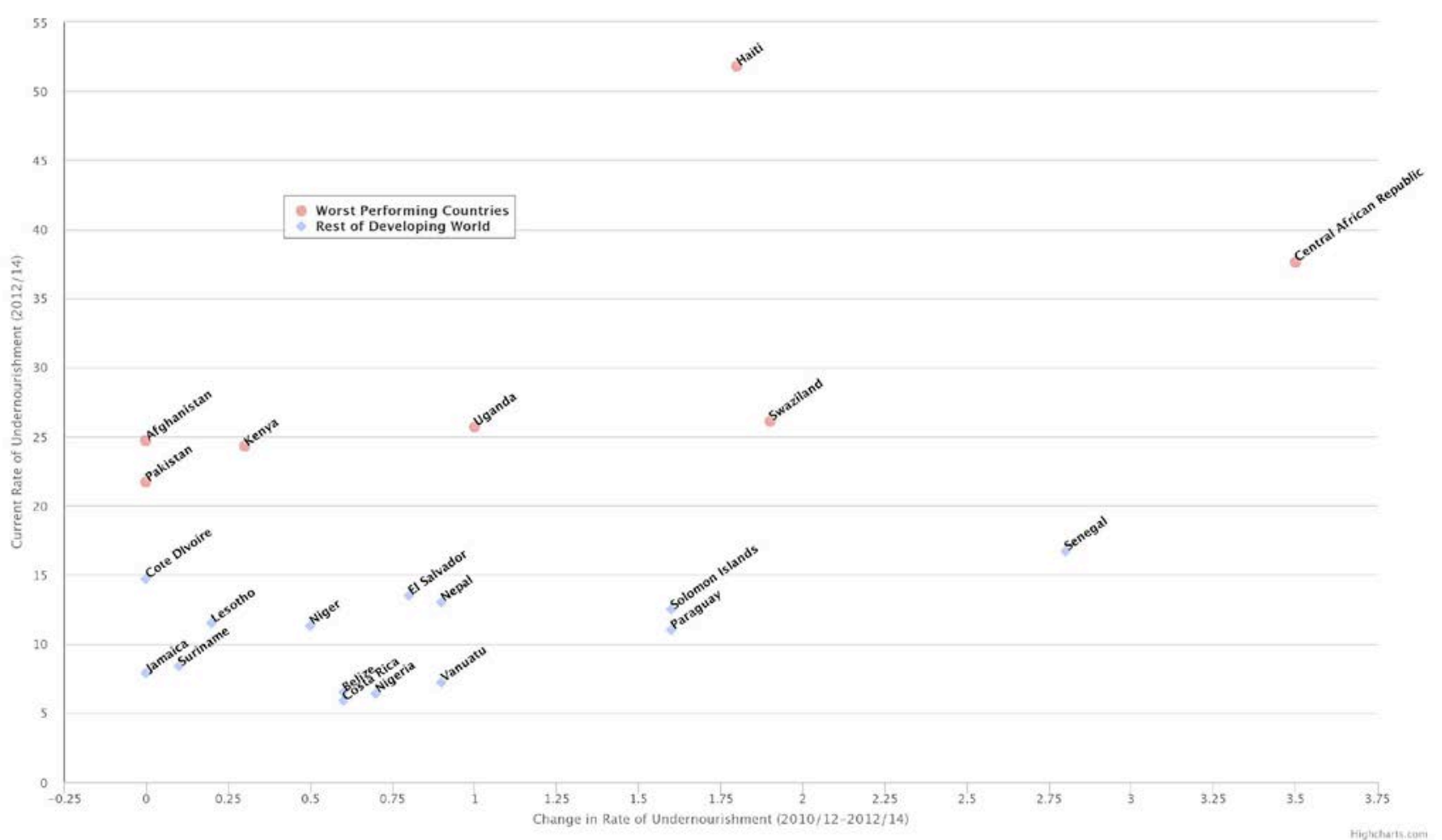

Figure 2. Change in Undernourishment (2010/12-2012/14) vs. Current Rate of Undernourishment (2012/14) - Countries with Increasing Undernourishment, Highlighting Worst Performing Countries 